\title{
Written work: the social functions of Research Ethics Committee letters
}

\author{
Dixon-Woods, M; Angell, E; Ashcroft, RE; Bryman, A
}

\author{
Manuscript published as: \\ SOCIAL SCIENCE \& MEDICINE 65 (4): 792-802 AUG 2007
}

\begin{abstract}
Research Ethics Committees (RECs) are increasingly institutionalised as a feature of research practice, but have remained strangely neglected by social scientists. In this paper we argue that analysis of letters from RECs to researchers offers important insights into how RECs operate. We report a content analysis and an ethnographic content analysis of 141 letters to researchers, together with an analysis of the organisational and institutional arrangements for RECs in the UK. We show that REC letters perform three important social functions. First, they define what is deemed by a REC to be ethical practice for any particular application, and confer authoritativeness on that definition. They do this actively, through comments on particular aspects of proposals, and passively, through silences about other aspects. Second, they provide an account of the work of the REC, and function as a form of institutional display. Third, they specify the nature of the relationship between the REC and the applicant, casting the applicant in a supplicant role and requiring forms of docility. Writing and reading REC letters requires highly specific competences, and engage both parties in a Bourdieusian "game" that discourages challenges from researchers. The authority of RECs' decisions derives not from their appeal to the moral superiority of any ethical position, but through their place in the organisational structure and the social positioning of the parties to the process thus implied. Letters are the critical point at which RECs act on researchers and their projects.
\end{abstract}




\section{Introduction}

Research Ethics Committees (RECs) have become increasingly institutionalised as an element of research practice worldwide and are charged with heavy responsibilities in the regulation and ethical conduct of research. In healthcare settings they are now commonplace, yet surprisingly neglected by sociologists as an object of study. Much of the commentary has come from health researchers, traditionally in the form of complaints about bureaucracy, delay, and stifling of research (Harries et al, 1994; Meade 1994; Watling and Dewhurst, 1993; Ahmed and Nicholson 1996; Redshaw et al. 1996). A particular focus of criticism has centered on apparent irrationality, incompetence, and "inconsistencies" in REC decision-making (e.g. Hannigan and Allen 2003; Lux et al. 2000; Edwards et al. 2004). It is only more recently that a social scientific analysis of RECs has begun to emerge, as the social science community itself has moved towards increased ethical oversight of research (e.g. Hammersley, 2006; Lincoln and Tierney, 2004; Van den Hoonard, 2001).

Notwithstanding the intensity of the debates, systematic empirical evidence about RECs and their operation is mostly lacking. Current evidence tends to be anecdotal, sometimes deriving from wounding encounters. An understanding of the role of RECs and its significance cannot be derived from such accounts alone; closer attention to the normal processes of REC functioning is much needed. In this paper we explore some of the ways in which RECs might be understood by taking up Prior's (2002) proposal that documents are an important (though often ignored) source for social science theorising. In particular, we examine letters written by RECs in response to submissions from applicants. In asking "what do REC letters do?", we propose that letters function socially in a number of important ways, and we suggest some of the consequences of this. In particular, we will argue that letters are acts themselves rather than mere reports of acts.

\section{Research Ethics Committees in the UK}

The European Clinical Trials Directive (Directive 2001/20/EC) makes it a requirement that applications to conduct clinical drug trials be considered and approved by an ethics committee. However, the UK Research Governance Framework (Department of Health, 2005) requires every research project - whether a clinical trial or not - to be conducted in the NHS to receive advice from an NHS REC. This framework effectively prevents those that do not receive a "favourable opinion" from proceeding, as such an opinion is necessary in order to gain permission from local NHS organisations to conduct the research.

In the UK, REC activities are coordinated by COREC (the Central Office for Research Ethics Committees), an organisation whose aims are to develop and implement operating procedures and standards for RECs that are consistent across the UK. Governance Arrangements for RECs (known as GAfREC, and published by COREC in 2001) define the remit and accountability of RECs, and give guidance on membership and the process of ethical review. Standard Operating Procedures (SOPS) were introduced in 2004, mainly to meet the obligations of the EU Directive. Under the SOPS, RECs in the UK are obliged to register each application they consider onto COREC's Research Ethics Database (RED). Applications are reviewed at REC meetings, where applications that have been scheduled for review are discussed by the committee. Applicants are invited to attend, and if in attendance may be invited to answer specific questions. The committee may further discuss privately any matters arising from the discussion, and a decision is made. RECs must also record the decisions made about applications, and may upload the letters written to applicants, onto the RED. Opinions, favourable or otherwise, must be given in writing. GAfREC (2001) states: 
7.9 The REC should always be able to demonstrate that it has acted reasonably in reaching a particular decision. When research proposals are rejected by the REC, the reasons for that decision must be made available to the applicant.

To fulfil the requirements of 7.9 might be thought to require that decisions be supported by documentation to show that each part of the decision has been arrived at through explicit consideration of the criteria described either in GAfREC or other relevant guidance, but in practice this would be impossibly onerous. One important question therefore concerns which specific issues are critical in arriving at a decision, or in justifying it formally.

GAfREC further specifies that:

9.21 Advice that is not binding may be appended to the decision.

9.22 In cases of conditional decisions, clear suggestions for revision and the procedure for having the application re-reviewed should be specified.

9.23 An unfavourable decision on an application should be supported by clearly stated reasons.

The guidance thus emphasises accountability to the researcher for the decisions reached, and moreover that reasons are required for unfavourable, but not for favourable, decisions.

The research reported here is concerned with letters to applicants conveying the decision of the REC at the first meeting at which the application was considered. RECs may make one of four possible decisions about each application. First, a "favourable" opinion means that the application is approved without further amendments. Between April and September 2005 (http://www.corec.org.uk/consultation/ApplicationDecisionsType.pdf), these constituted about $15 \%$ of decisions made by RECs at first consideration of an application. Second, a "provisional" (or "conditional") opinion, which in the same time period constituted $64 \%$ of decisions, requires applicants to make a response to the REC addressing issues raised in the letter before a final opinion is issued. Third, an unfavourable opinion (6\% of all submissions in the same six month period) prevents the researcher for progressing with their project, and gives options either to resubmit a new application (taking into account the issues raised) or to appeal (in which case no changes can be made to the documentation). Finally, RECs may decide that applications are "outside remit" or that advice should be sought from an external expert before an opinion can be given.

\section{Methods}

We aimed to sample letters from the Research Ethics Database (RED) maintained by COREC. We focused on letters that received provisional and unfavourable decisions only in response to full applications (thus excluding amendments to existing projects etc). Uploaded letters are stored on the RED according to the REC that considered the application, and according to the meeting at which it was considered. Criteria for inclusion of a letter in our sample were as follows:

- The letter conveyed a "provisional" or "unfavourable" opinion.

- The letter concerned an application considered by a REC for the first time during our "eligible periods": July 2005, October 2005, January 2006 and April 2006. These periods were chosen to minimise seasonal effects in application submission.

The 55 RECs who did not upload letters to the RED were excluded. The first letter that met our eligibility criteria for each of the 115 RECs who did upload letters to the RED was chosen for inclusion in the study. Unfavourable opinions were purposefully over-represented to yield sufficient letters for analysis, so that they formed $20 \%$ of the initial sample. The remaining $80 \%$ of letters were those applications with provisional opinions. Applications that initially received a provisional decision but were subsequently issued with an unfavourable opinion were of particular 
interest. However, none was identified in the periods from which we had sampled, so all applications meeting the criterion of "first provisional, then unfavourable" between March 2004 and July 2006 for which a letter was available were included in the study. Descriptive information about each application - e.g. clinical drug trial, qualitative study, student project etc - was recorded. All letters were anonymised.

\section{Analysis}

We used two forms of content analysis: first, a traditional content analysis approach (Holsti, 1969) and second, ethnographic content analysis (Altheide 1996, 2004). Content analysis provides a consistent and transparent examination of categories which can then be expressed in terms of frequencies. We derived seven categories from GAfREC (Governance Arrangements for Research Ethics Committees, COREC, 2001) to make broad classifications of issues. These categories were: scientific design and conduct; participant recruitment; care and protection of participants; confidentiality; informed consent; community considerations; and documentation. An "outside-GAfREC" category was added to classify issues that appeared to be outside the remit of GAfREC.

Ethnographic content analysis enabled a further, more detailed analysis, and required the development of a coding scheme grounded in the data. The coding scheme was generated initially through close inspection and comparison across the texts of letters used in a previous controlled comparison of REC decisions by all authors (Angell et al, in press), but was modified in response to the new data in this study. Explicit specifications were devised to aid data assignment, which was facilitated by the use of QSR N6 software. Coding was undertaken by EA, and independently checked by MDW. Quotations used to illustrate the analysis have had identifying details removed or modified to further preserve anonymity.

This work was supplemented by an analysis of the organisational context of REC decisionmaking, conducted using a review of procedures and documents on the Central Office for Research Ethics Committee's website (www.corec.org.uk) and drawing reflexively on our experiences within the team as applicants (MDW, REA), REC member (REA), REC trainers (MDW, EA. REA) and REC administrator (EA). This project was deemed by COREC not to require Research Ethics Committee review.

\section{Findings}

Our sample included 141 letters with varying decisions (Table 1). Our analysis of REC letters identified three important social functions that these letters perform: first, defining what is ethical, second, demonstrating the work of Research Ethics Committees, and third, specifying relationships between committees and applicants.

\section{Function 1: Defining what is ethical}

Content analysis of letters demonstrated that RECs have a repertoire of options available to them as they consider any particular application, and that they select from these in coming to decisions and offering "opinions" to applicants. Our purpose here is not to explore the bases of these decisions, but to show that RECs are sites of discretionary judgement: there is no single "right" answer to (most) ethical issues, at least in the context of medical research. Although there may well be consensus on some issues, in most cases there is room for interpretation and judgement. Philosophically, there is the difficulty of fixing the correct answer in specific situations of quite general normative rules. Most moral philosophers accept that, given that there is a range of ways of approaching ethical issues (utilitarian versus human rights, for example), it is possible for 
different positions to be produced - but there is not necessarily any way of deciding which one is the "right" one.

Without a final moral authority in determining the reasonableness or otherwise of RECs' decisions, it is likely to be impossible to specify what should have been the "correct" response to any particular application. In the face of the equivocal nature of ethical decision-making, the social function of the REC letter is to fix the meaning of "what is ethical?" for each application. Crucially, therefore, the letters function to define what is deemed by a REC to be ethical practice, and confer authoritativeness on that definition.

REC letters fix the meaning of "what is ethical" in two distinct senses. First, they identify the features of the proposal which are the ethical topics or issues that engage REC scrutiny and concern. In some instances, it may be quite obvious what is to count as an ethical issue - for instance, the consent arrangements in the study - not least because GAfREC requires particular attention to these. In other cases, it is less obvious what is to count as an ethical issue, or why it might engage the attention of the REC.

Second, REC letters actively or passively prescribe what ethical conduct requires in regard to these ethical issues. If the REC does not comment in the letter on researchers' proposed arrangements, it is in essence passively accepting the researchers' proposals. If the REC does comment, it is actively prescribing some amendment to the researchers' proposals. In so doing, letters may impose a range of highly varying requirements on researchers. For example, in looking at a question such as that of length of time data should be stored, our analysis identified a range of different obligations, even when apparently similar types of projects were under review. All of the examples that follow involve questionnaires, for example:

..the committee requested that data be stored for 5 years. (Letter 19, provisional opinion)

It was suggested that it would be more appropriate to keep the data for 3 years. Please confirm that you will be keeping the data for 3 years (Letter 22, provisional opinion).

The data from the study should be kept for one year after your qualification has been awarded unless you can give a specific reason to keep it longer. (Letter 44, provisional opinion)

The Committee advises that data should be stored for 7 years. (Letter 58, provisional opinion)

The engagement of RECs with issues of data storage illustrates not only the variability of REC recommendations and the way that letters fix the requirements for each project, but also the contestable nature of such decisions and the way they interact with issues of governance. It could be argued, for example, that length of data storage is not prima facie an ethical issue, and that there is no way of determining the "most correct" length of time.

Although they showed significant diversity in their approaches to some issues, REC letters were consistent in their approaches to others (though often differing in specific details). There was agreement, for example, that research participants' direct expenses should be reimbursed, though not to a level where they might be an inducement:

Expenses should be offered for travel and child care. (Letter 33, unfavourable opinion)

It is felt that stating a specific sum of money could sound coercive. Please alter this to "any out of pocket expenses would be met" but the sum should not be specified, although it could be up to $£ 20$ if necessary. This way it would not sound like an inducement." (Letter 52, provisional opinion) 
A34 of the Application Form states 'travel expenses of up to ten pounds will be offered to participants'. The Committee felt that ten pounds may not be enough and suggested this is replaced with 'reasonable travel expenses will be offered' (Letter 87, provisional opinion)

The Committee felt that travel expenses should be provided for participants. Please detail for the Committee how this will be addressed." (Letter 139, provisional opinion)

Though clearly RECs are making firm recommendations to researchers in these examples of both consistent and inconsistent advice, the source of ethical authority for the REC in coming to their conclusions is rarely explicit in the letters. GAfREC - which provides the framework within which RECs are expected to work - is not referred to in any of the letters in our sample. Specific ethical principles or even guidelines are rarely invoked explicitly, and when they are, it is to authenticate or legitimise the decisions of the committee, as in this reference to dignity:

... [Members] were particularly concerned to protect a patient's privacy and dignity regarding the bedside interviews and that the patient should not be caused further confusion (Letter 95, provisional opinion)

The absence of external referents in these letters reinforces the implication that the source of the REC's authoritativeness is the REC itself., The authority of the REC letter derives from its organisational and institutional location and status, the processing of the application within the remit and procedures granted to the REC, and the REC's exercise of its role as a moral authority.

An important and recent source of influence on REC letters, however, is the presence of researchers at meetings of the committee. Letters vary in how they handle what the researcher has said at the meeting, with some simply noting the attendance of the researchers, others reporting the outcome of a dialogue where the queries of the REC had been satisfactorily addressed, and others suggesting that the REC continued to disagree with the researcher or impose further requirements following researcher attendance.

The applicant attended (Letter 5, provisional opinion)

Members were concerned that giving a strong analgesia would make the patients drowsy and therefore unable to give informed consent. ANSWER: The patients are normally given a non-sedative drug. (Letter 13, provisional opinion)

As discussed with you at the meeting, there is a possibility of various types of disclosure arising out of interviewing staff members from one small team. The participant information sheet should make clear what you would do in the event that this occurs. (Letter 86, provisional opinion)

The Committee suggested that the study could infer doctor blame for delays in referral. $<$ Named researcher> confirmed that the study did not focus on doctor delay and that they were also not blaming the patient. (Letter 89, unfavourable opinion)

It is clear that in some of these examples at least, the researcher is contributing to the "coproduction" of the letter, and that statements made by the researcher can be incorporated into the letter. However, it is also clear - in the example of the unfavourable opinion, for instance - that it remains for the REC to determine how far the researcher's responses were satisfactory, and that it is what is written in the letter - rather than what is said in the meeting - that stabilises what is "ethical" for any particular application. 


\section{Function 2: Demonstrating the work of the Research Ethics Committee}

Our analysis suggests that REC letters take on characteristic forms, in compliance with prescribed procedural norms. They are addressed directly to the Chief Investigator and state the title of the study and REC reference number, list the documents reviewed, specify whether sitespecific assessment will be required, list the members who attended the meeting, and give a statement of compliance. However, the form and content of the remaining elements of individual letters is only weakly prescribed by formal rules, leaving room for considerable discretion, usually exercised by the REC chair or coordinator (administrator), as to form and phrasing. Some offer a précis, then give the detail in list form; others simply list (in no particular order) the issues raised; and some distinguish between essential requirements and optional suggestions for a favourable opinion. If the applicant attended the meeting, the letter may describe details of the attendance, then comment on other issues that were discussed in private. Letters issuing an unfavourable opinion also explain how the applicant can appeal or re-apply.

Clearly, letters are the "front stage" (Goffman, 1959) of the work of RECs, providing a public trace of the discussions that occurred "backstage". In this, one of the key functions that the letters serve is that of demonstrating the work of RECs. Thus it is uncommon to find letters that are short, or that give a "favourable" opinion in response to the first overture made by an applicant: only $15 \%$ of submitted applications receive a favourable opinion at first review, as noted above. Instead, letters operate as "displays" of the application having been through due process, and of the care, thoroughness, and thoughtfulness of the REC. The diligence exercised by RECs is indicated by use of a stylised language, frequently involving use of active verbs such as "considered", "queried", "questioned" "asked". Many comments are at the level of detail:

Remove statement ". . . we will be able to help to improve the lives of children and families affected." The Committee considered this to be an overstatement. Remove statements regarding searching for the gene as the sample size is not sufficient to exclude candidate genes. Information sheet for parents to include approximate time to complete questionnaires. (Letter 15, provisional opinion)

The committee suggested that you may like to open the invitation to the interview element of this study to all patients being sent the questionnaire. If you wish to do this then it is suggested that you include additional information on the invitation letter with a tear off slip for patients to respond and a contact telephone number. If you decide to do this, at this stage, then you will need to send a copy of the letter for approval by the committee. Alternatively, you may wish to consider including this element to the study later on and this can be achieved by completing a form for a protocol amendment and submitting to the committee for approval at the appropriate time. (Letter 22, provisional opinion)

The rhetorical strategies embedded in such texts do more than act as a set of instructions to applicants about the ethical status of their applications. The letters also serve to deflect challenges about the pains taken by the committee, and give a single, consistent, apparently rational account of the considerations of the committee.

In the examples above (as in many others in our sample), the letters also serve to underline the role of the REC as the patient's advocate and to align the REC with the interests of an apparently vulnerable group. For RECs, then, letters function as warrants that they have done their work, are accountable, and are therefore to be trusted. They function, therefore, as a form of "institutional display" (Goffman, 1961). Sometimes, our sample suggests, REC letters may fail to achieve this aim. Some letters were poorly punctuated, did not provide reasons or arguments to explain the REC's requests, or might be considered as "rude": 
...you had indicted [sic] individuals being "contacted by telephone or letter" but an example of the introductory letter had not been provided. (Letter 82, provisional opinion)

Does you [sic] expect the treatment to be equally effective in both groups? (Letter 139, provisional opinion)

The one page advert supplied in the submission pact [sic] is inadequate and requires reworking. (Letter 134, provisional opinion)

However, these lapses should not be taken to detract from the general and overwhelming impression that RECs couch their discourse in a manner that is a display of their authority and authoritativeness in the realm of ethical decision-making.

\section{Function 3: Specifying relationships}

A third function of REC letters is to routinise and prescribe relationships between RECs and applicants. Here, an understanding of the organisation and institutional context is important. REC letters are produced as part of a highly standardised, routinised set of procedures, in which the roles of both applicant and REC are constrained. Recent years have seen significant formalisation and rationalisation of the operation and constitution of RECs. Standard Operating Procedures (SOPs), including strict timelines, have been imposed, virtually eliminating variations in application procedures (Department of Health 2005). From the applicant's side, this includes a submission of a prescribed set of documentation, including an electronic application form, protocol, participant information sheets and consent forms, any data collection instruments (e.g. questionnaires, diary cards, interview schedules), evidence of prior scientific peer review and curricula vitae.

To apply to a REC, a researcher must first "book" an agenda slot at a REC meeting in his/her capacity as the "Chief Investigator" for the project proposed. The researcher must send the documentation for the application - using COREC approved forms - to arrive at the REC office within five working days. A "clock" begins to tick as soon as a valid application is received, with RECs obliged to deliver a decision within 60 days of receipt. A "validation letter" is issued to the applicant listing the documentation received and inviting the researcher to attend the REC meeting or be available by phone, though neither is compulsory.

The REC coordinator must notify the applicant by letter of the decision of the REC within 10 working days of the meeting. In the case of provisional opinions, the concerns raised by the REC are described in the letter and the applicant is invited to respond. The "clock" stops while the REC is awaiting a response from the applicant, and begins again as soon as a "complete" response is received. If the response is satisfactory, a favourable opinion can be issued; if unsatisfactory, the REC may issue an unfavourable opinion. If the majority - but not all - of the REC's concerns were addressed satisfactorily, the REC may deem the application "incomplete", and allow the applicant a "second chance", but may not raise new issues. Because such applications are considered "incomplete", the clock remains stopped while the applicant responds. Applications with an "unfavourable" opinion can only be resubmitted if substantially amended. An appeal option, where the application is sent to another REC, is also available for unfavourable opinions, but if this applicant appeals, s/he may not alter the application in any way: it is sent to another REC as is, along with the letter from of the first REC. The researchers may choose the REC to which it is sent.

The nature of this organisational context means that both researchers and RECs are focused on what needs to be done to get a "favourable opinion" for the research. This is vital to researchers for many reasons. Not only is it required in order to conduct research within the NHS, but it is also needed in order to claim the right to deem certain activities as "research". Many of the activities that are undertaken as "research" are in fact agnostic as to their ultimate purpose: interviewing, 
medical record review, administration of psychological tests, taking of blood samples are all examples of activities that may be carried out as part of routine clinical activity, audit, or other "non-research" procedures; in order for them to be called "research", they must be licensed as such by a REC. Thus, although there is a guidance on how research, audit, and service evaluation might be distinguished (COREC, 2006), applicants may need the imprimatur of the REC in order that their particular project be determined to be "research".

The organisational and institutional context in which these authorisations and permissions must be sought is highly constrained by pressures of time and other demands. Clocks begin (and cease) ticking at pre-determined times, and researchers may have financial or other important reasons for getting on with their work. In this context, researchers and RECs must work out the rules of the game that form the logic of practices, deploy or 'invest' their capital in the game, and draw on their knowledge of their positioning within that field; above all, they must accept the 'illusio' - the social reality of the game (Bourdieu and Wacquant, 1992). In particular, they must understand the roles and relationships involved in this game, and letters play a critical part in structuring these.

In understanding how it is that letters function socially to specify relationships between RECs and applicants, we draw upon the notion of "interpretive communities" as developed by Fish (1980). We suggest that those involved in the process know how to "read" the letters so that they will be understood in particular ways. Thus, for example, what are implied to be "requests", "suggestions", "recommendations" or forms of advice, will be interpreted as commandments and requirements by a competent reader. Some statements function as "instructions", as follows:

Independent statistical advice for this study should be sought from <named statistician>. (Application 6, unfavourable opinion)

The information sheet should clearly explain that researchers may access information from patients' clinical notes for the purposes of this study. (Application 7, provisional opinion)

These can be readily distinguished from more genuine "suggestions":

The Committee agreed that the Researcher should consider audio taping the Focus Groups, instead of taking notes. If the Researcher decided to audio tape the Focus Groups, this should be made clear in the Participant Information Sheet (PIS) (Letter 77, unfavourable opinion)

Should you consider excluding those patients whose vision is affected by their stroke? (Letter 95, provisional opinion)

We further suggest that within the organisational arrangements for ethical approval, the scripting of these letters reinforces a ritualised supplicant-authority relationship between applicants and committees. Applicants must "submit" (the verb is used explicitly) to the committee; must make full disclosures and display their credentials as competent, trustworthy researchers; and must permit the exposure of their proposal to critical scrutiny. The REC letter is the outcome of that "submission". To the competent reader of letters, it is clear that the proper role of applicants is one of docility; in responding to letters, they must make displays of obedience and deference. In particular, unless they are to resort to the appeals mechanism, applicants are obliged to accept judgements which are inherently contestable and indeterminate as incontestable and final.

The appeals mechanism in theory offers a means by which applicants may challenge RECs. In practice, however, once a letter has established the ethical provenance of an application, it is difficult for the applicant to escape the account of what is ethical thus created. The appeals 
mechanism can be activated only in the case of an unfavourable decision, and only a small proportion of unfavourable decisions are appealed. Perhaps more significantly, given a letter conveying a provisional decision that makes clear what researchers are to do if they are to be given a favourable opinion, few options other than to comply are, in practice, available. If a researcher were to "disagree" with recommendations made by the REC regarding the amendments required to turn a provisional decision into a favourable one, the REC is obliged to either accept the researcher's argument and give a favourable opinion, or to reject the argument and give an unfavourable opinion: the researcher who disagrees therefore takes a significant risk of an unfavourable opinion. In the event of an unfavourable opinion, the delays associated with going through an appeals process introduces further delays may not be tolerable. It is likely that this knowledge makes applicants disinclined to challenge what in many cases is challengeable, given the contestable nature of many ethical decisions and the contexts of their application.

\section{Discussion}

Our analysis suggests that, in important ways, letters to applicants both are and do the work of Research Ethics Committees. REC letters structure the research environment both through what they say and what they do not say; they create and sustain relationships between RECs and applicants; and they act as a form of licence for the conduct of research. The letters provide a means of stabilising "what is ethical" in a world where ethical matters are in fact indeterminate. Our analysis thus suggests that it may be difficult to identify any particular characteristic of an application that makes it "ethical" or "unethical"; what determines whether an application is "ethical" is whether a REC letter gives it a favourable opinion.

The work of RECs is explicitly one of judgement and discretion; each application is different, and there is no absolute single "right answer" to most of the questions that confront committees. Their work might more appropriately be compared with making aesthetic judgements - in which there is an appeal to an ideal - rather than making rule-based judgements, in which there is an appeal to a codified standard. A key question thus concerns the authority on which the REC rests. Our analysis suggests that the institutionalisation of the REC as the moral authority serves to legitimate and authorise a particular opinion for a particular application, but it does so not through an appeal to the moral superiority of any ethical position, but through its place in the organisational structure and the social positioning of the parties to the process thereby implied. Of course, this is not to imply that REC decision-making has no inherent moral standing; RECs derive claims to moral standing from the selection and training of REC members, through the guidelines and norms of the REC community (even if these are not explicitly referred to), through the care and thoroughness with which they scrutinise applications, and - more recently - through their engagement with researchers who attend meetings and may help to "co-produce" letters..

Moreover, the REC's power to determine what is ethical is not absolute. REC decisions are subject to procedural constraints (such as the opportunity for re-review by an alternative committee, or judicial review by the courts of the reasonableness of their decisions). Should a disaster materialise in the research project, RECs can come under intense scrutiny as to the wisdom of its decisions (as with the TeGenero TGN 1412 disaster, (Bloomberg News 2006)). On a more everyday level, RECs are involved in a continuous dialogue with researchers, the Central Office for Research Ethics Committees and the regional Offices for Research Ethics Committees, and other parties. As GAfREC states, their decisions must be seen to be reasonable, even if it is reason backed by authority. As such, RECs exercise discretion within a framework of rules and (more or less) shared expectations with their clients (Mashaw, 1983). But within this context, it is the letter that constructs the ethical status of researcher's application.

Understanding what is needed to gain ethical approval involves applicants in being competent in the Bourdieusian "game" being played, and in particular having the competence to make the appropriate displays - of docility, of deference, of submission, and understanding themselves to be supplicants. Letters themselves also engage in institutional displays, where they aim to function as displays of deliberation, critical judgement, discernment, moral rectitude, allegiance 
to "the patient", and thoroughness. The orderliness and consensus of the REC letter further functions to obscure the messy world of tensions, argument, debate and conflicts that characterises all organisational life. Writers such as Weick (1969) have argued that organisations are frequently, if not invariably, faced with the need to project a public face of certainty, even though organization theorists have long recognised that organisations are internally characterised by "ambiguity, ambivalence, and equivocality" (Czarniawska, 2005). This is likely to be even more apparent in areas of organisational life and decision-making where decisions involve dilemmas (Billig et al., 1988). This is the realm in which RECs operate. Not only are they confronted with the diverse uncertainties of organisational life, but they are concerned with matters of ethics which are themselves profoundly equivocal and contestable. Nonetheless, they must engage in displays of certitude deriving from institutionalised ethical norms, which are themselves products of attempts to routinise the disputable. The requirement to provide a confident statement in the face of equivocality provides some of the explanation for the authoritative (perhaps even authoritarian) tone of some of the letters discussed here. The "contrary themes" (Billig et al. 1988) that pervade ideological thinking have to be suppressed in order to accommodate this organisational requirement.

Part of the difficulty for researchers is, of course, that there is no recognised external epistemological standpoint against which to assess whether the REC decision is "correct". Although it might be possible to cite formal guidelines indicating that there is another ethical view of an issue that differs significantly from the REC's decision, this does not trump the REC's decision. Nor does evidence that RECs have reviewed a similar proposal in the past and come to a different conclusion function as a "precedent". In this, RECs' operation as a moral authority where they command the power to determine what is ethical - shares many of the characteristics of other agencies involved in making decisions about research: funders, editors, and referees. These agencies frequently produce decisions, and accounts of decisions, that researchers find difficult to accept. In many of these cases, what is being contested between the research team and those involved in judging the research are issues concerning the quality of the science, which are very often the subject of intense disagreement. In the case of science, these judges function as the locations of what Starr (1982) terms "cultural authority" - the ability to ensure that particular definitions of reality will prevail as valid and true, just as REC letters function to stabilise what is valid and true from a moral perspective. What both forms of authority share what Goffman (1959) identifies as the power to define the situation.

REC letters in this context exemplify key features of the practice of "giving reasons" as analysed by Charles Tilly (2006): giving reasons involves defining the relationship between reason-giver and reason-recipient within a framework of the practice of reason-giving appropriate to that relationship. In the case of REC review, giving reasons implies not only that the recipients are entitled to reasons (it is not an absolute despotism), but also that these reasons need to the kind of reasons both parties can recognise as good reasons. In many cases of trouble between REC and applicant, failure to agree a shared understanding of what makes for a good reason is at the heart of the trouble. In practice, if a REC deems some feature of a proposal an ethical issue, it is a brave researcher who would dispute their authority to do so, or challenge their prescriptions, unless very sure of his or her ground.

An important question concerns the impact of REC letters on what research questions are asked, and by whom. Rather than conceiving of RECs as the passive recipients of applications sourced in the research environment, it will be clear that RECs in fact actively structure and help to create that environment. Thus an aspect of what is important about our sample of letters concerns what is absent rather than what is present; in other words, the silences rather than the voices in these texts. 


\section{Conclusions}

The manifest role attributed to RECs is one of assessing and adjudicating upon the ethical character of applications. In this, they are charged with a peculiar, and mysterious, task. Ethical questions have a particular character of "unknowability", yet the NHS and legal structures we have described institutionalise RECs both as a moral authority and as universalistic organisations - bureaucracies in the Weberian sense - expected to evaluate and adjudicate upon applications based on universal principles. Letters to researchers from Research Ethics Committees perform important social functions in the exercise of this role. They can be seen as the critical point at which RECs act on researchers and their projects, as distinct from the more passive role played by guidelines, codes and norms of conduct. Letters are not simply reports of the discussions and decisions of RECs, but act to specify what is ethical for any particular application; to give an account of the committee; and to routinise relationships between RECs and researchers.

\section{References}

Ahmed, A.H. and Nicholson, K.G., 1996. Delays and diversity in the practice of local research ethics committees. Journal of medical ethics, 22(5), 263-266

Altheide, D.L. Ethnographic content analysis. In: Lewis Beck MS, Bryman A, Liao TF, editors. The Sage Enclycopaedia of Social Science Research Methods Thousand Oaks, Ca.: Sage; 2004.

Altheide, D.L. Qualitative Media Analysis. Thousand Oaks, Ca.: Sage; 1996.

Angell EL, Jackson CJ, Ashcroft RE, Bryman A, Windridge K, Dixon-Woods M. Is

"inconsistency" in Research Ethics Committee decision-making really a problem? An empirical investigation and reflection. Clinical Ethics (accepted December 2006)

Billig, M., Condor, S., Edwards, D., Gane, M., Middleton, D. and Radley, A. 1988. Ideological Dilemmas: A Social Psychology of Everyday Thinking. London: Sage.

Bloomberg News (2006). (David Evans) Parexel misled subjects sickened in London study, ethicists say. 22 April 2006.

http://www.bloomberg.co.uk/apps/news?pid=20601186\&refer=special report\&sid=aG3sg1rlkL4U (Accessed 25/09/2006)

Bourdieu, P. Wacquant L. (1992) An Invitation to Reflexive Sociology. Chicago: Chicago University Press

Central Office for Research Ethics Committees, 2001. Governance Arrangements for Research Ethics Committees (GAfREC). London: COREC

Central Office for Research Ethics Committees, 2005. Standard Operating Procedures for Research Ethics Committees. Version 3.0. London: COREC. 
Central Office for Research Ethics Committees, 2006. Diffferentiating audit, service evaluation and research.

http://www.corec.org.uk/recs/guidance/docs/ls and As Differentiating Research.pdf (accessed 24/01/2006)

Czarniawska, B. 2005. Karl Weick: concepts, style and reflection. Sociological Review, 53 (S1), S267-S278.

Department of Health, 2006, Research governance framework for health and social care. London: Department of Health 2nd ed. http://www.dh.gov.uk/assetRoot/04/12/24/27/04122427.pdf (accessed 15 June, 2006).

Department of Health, 2005. Report of the Ad Hoc Advisory Group on the Operation of NHS Research Ethics Committees. London: Department of Health http://www.dh.gov.uk/assetRoot/04/11/24/17/04112417.pdf (accessed 30 May, 2006).

Directive 2001/20/EC of the European Parliament and of the Council of 4 April 2001. The approximation of the laws, regulations and administrative provisions of the member states relating to the implementation of good clinical practice in the conduct of clinical trials on medicinal products for human use. Official J Eur Communities. 2001;1;L 121/34

Edwards, S.J.L., Ashcroft, R.E., Kirchin, S. 2004. Research Ethics Committees: Differences and moral judgement. Bioethics 18, 408-427

Fish, S. (1980) Is there a text in this class? The authority of interpretative communities. London: Harvard University Press

Goffman, E. (1959) The presentation of self in everyday life. New York: Doubleday.

Goffman, E. (1961) Asylums: essays on the social situation of mental patients and other inmates Garden City, NY: Anchor

Hammersley M. (2006) Are ethics committees ethical? Qualitative Researcher 2: 4-8

Hannigan, B., Allen, D., 2003. A tale of two studies: research governance issues arising from two ethnographic investigations into the organisation of health and social care. International journal of nursing studies, 40(7), 685-695

Harries, U.J., et al, 1994. Local Research Ethics Committees - Widely Differing Responses to a National Survey Protocol. Journal of the Royal College of Physicians of London, 28(2), 150-154.

Holsti, O.R. (1969) Content Analysis for the Social Sciences and Humanities. Reading, Mass.: Addison Wesley

Lincoln, Y.S., Tierney, W.G. (2004) Qualitative research and institutional review boards. Qualitative Inquiry. 10: 219-234

Lux, A.L., Edwards, S.W. and Osborne, J.P., 2000. Responses of local research ethics committees to a study with approval from a multicentre research ethics committee. BMJ, 320 : 1182-1183.

Mashaw, J.L., 1983. Bureaucratic Justice: Managing Social Security Disability Claims New Haven: Yale University Press. 
Meade, T.W., 1994. The Trouble with Ethics Committees. Journal of the Royal College of Physicians of London, 28(2), 102-104.

Merton, R.K., 1936. The unanticipated consequences of purposive social action. American Sociological Review 1, 894-904

Prior, L. (2002) Using documents in social research. London: Sage

Redshaw, M.E., Harris, A. and Baum, J.D., 1996. Research ethics committee audit: differences between committees. Journal of medical ethics, 22(2), 78-82.

Starr, P. (1982) The social transformation of American medicine. New York: Basic Books

Tilly, C. (2006) Why? Princeton, N.J.: Princeton University Press

Van den Hoonaard, W. (2001) Is Research Ethics Review a moral panic? Canadian Review of Sociology and Anthropology 38: 19-36

Watling, M.I.L. and Dewhurst, J.K., 1993. Current Experience of Central Versus Local Ethics Approval in Multicenter Studies. Journal of the Royal College of Physicians of London, 27(4), 399-402.

Weick, K.E. 1969. The Social Psychology of Organizing, Reading, Mass: Addison-Wesley.

\section{Table 1: Final decisions in relation to applications in our sample}

\begin{tabular}{|c|c|c|c|}
\hline Decision & $\begin{array}{l}\text { Non- } \\
\text { student }\end{array}$ & Student & Total \\
\hline Provisional opinion and awaiting response & 1 & 0 & 1 \\
\hline Provisional opinion then favourable & 54 & 31 & 85 \\
\hline Provisional opinion then unfavourable & 17 & 9 & 26 \\
\hline Provisional opinion then withdrawn by REC & 1 & 0 & 1 \\
\hline $\begin{array}{l}\text { Provisional opinion then withdrawn by } \\
\text { researcher }\end{array}$ & 3 & 2 & 5 \\
\hline Unfavourable opinion at first review & 14 & 9 & 23 \\
\hline Grand Total & 90 & 51 & 141 \\
\hline
\end{tabular}

